\title{
Tecnologia móvel e dislexia: possibilidades pedagógicas inclusivas pela interface do appmobile "silabando"
}

\author{
Mobile technology and dyslexia: inclusive pedagogical possibilities through the \\ appmobile interface "silabando" \\ Tecnología móvil y dislexia: posibilidades pedagógicas inclusivas por la \\ interfaz del appmobile "silabando" \\ CARLA SALOMÉ MARGARIDA DE SOUZA \\ MARLENE BARBOSA DE FREITAS REIS \\ GISLENE DE FREITAS \\ LILIAN CRISTINA DOS SANTOS
}

\begin{abstract}
Resumo: Este artigo discute políticas públicas de inclusão e apresenta uma proposta de intervenção para discentes com dislexia, baseada na tecnologia móvel. Trata-se de uma pesquisa qualitativa realizada em duas etapas: na primeira, buscou-se fundamentar as concepções e intersecções da tríade: dislexia, políticas públicas de inclusão e tecnologia móvel; na segunda, foi feito um estudo exploratório, a fim de analisar o aplicativo móvel "Silabando". Os resultados apontam que o uso pedagógico do aplicativo pode otimizar a aprendizagem das crianças disléxicas e, consequentemente, favorecer sua inclusão.
\end{abstract}

Palavras-chave: Dislexia. Políticas públicas de inclusão. Aplicativo móvel.

Abstract: This article discusses public inclusion policies and presents an intervention proposal for students with dyslexia, based on mobile technology. It is a qualitative research carried out in two stages: in the first, we tried to base the conceptions and intersections of the triad: dyslexia, public policies of inclusion and mobile technology; in the second, an exploratory study was done to analyze the mobile application "Silabando". The results indicate that the pedagogical use of the application can optimize the learning of dyslexic children and, consequently, favor its inclusion.

Keywords: Dyslexia. Public inclusion policies. Mobile application.

Resumen: Este artículo discute políticas públicas de inclusión y presenta una propuesta de intervención para discentes con dislexia, basada en la tecnología móvil. Se trata de una investigación cualitativa realizada en dos etapas: en la primera, se buscó fundamentar las concepciones e intersecciones de la tríada: dislexia, políticas públicas de inclusión y tecnología móvil; en la segunda, se hizo un estudio exploratorio, a fin de analizar el aplicativo móvil "Silabando". Los resultados apuntan que el uso pedagógico del aplicativo puede optimizar el aprendizaje de los niños disléxicos y, consecuentemente, favorecer su inclusión.

Palabras clave: Dislexia. Políticas públicas de inclusión. Aplicación móvil. 


\section{INTRODUÇÃO}

A Dislexia é um distúrbio de aprendizagem caracterizado pela dificuldade de leitura e escrita. Essas dificuldades resultam de uma insuficiência no processo fonológico e são inesperadas em relação à idade (MAIA, 2016).

Estudos realizados por Navas et al.(2017) demonstram que o Brasil tem aproximadamente $4 \%$ de pessoas disléxicas e que grande parte dessas ainda não recebem o atendimento educacional adequado para suprir suas necessidades. De acordo com os pesquisadores, "a maioria deste contin-gente se encontra sem diagnóstico e negligenciado no atendimento de suas necessidades educacionais especiais"1 (NAVAS et al., 2017, p. 5).

Essa situação faz emergir a necessidade de implementação de políticas públicas de inclusão que garantam o direito de aprendizagem aos discentes com dislexia, bem como ratificar o papel do estado na efetivação dessas políticas, para que, de fato, a educação consiga oferecer acessibilidade de aprendizagem a todos.

Chamamos a atenção neste trabalho para a consolidação de uma política educacional que contemple o atendimento às necessidades específicas dos alunos com dislexia e que respalde o redimensionamento das práticas pedagógicas das escolas. Ademais, que estabeleça diretrizes para a formação continuada dos docentes, passando desde a disponibilização de recursos materiais simples até os recursos mediados pelas novas tecnologias de informação e comunicação, aqui com destaque para a tecnologia móvel em smartphones e tablets, um dos assuntos deste artigo.

Essas novas tecnologias, também denominadas Tecnologias Digitais de Informação e Comunicação (TDIC), têm transformado o modo com que compreendemos o tempo, o espaço e a forma como nos comunicamos e aprendemos. Sua principal marca é a digitalização e a comunicação em rede, com destaque para a tecnologia móvel, que vem consolidar uma nova forma de aprendizagem denominada mobile learning ou aprendizagem móvel. A aprendizagem móvel oferece formas inovadoras que ajudam no processo de aprendizagem por meio de aparelhos móveis, como notebooks, tablets, MP3 players, smartphones e telefones celulares (UNESCO, 2014).

Esses aparelhos, ainda conforme a Unesco (2014), possuem a tecnologia mais onipresente e bem-sucedida da história da humanidade. Eles existem em grandes quantidades, em lugares onde livros e escolas são escassos, pois “os aparelhos móveis facilitam a aprendizagem, ao superar os limites entre a aprendizagem formal e a não formal” (UNESCO, 2014, p. 23).

1 Conforme Carvalho: “[...] especiais devem ser consideradas as estratégias que a prática pedagógica deve assumir para remover as barreiras para a aprendizagem” (2000, p. 17). 
Essa demanda nos coloca diante das seguintes inquietações: em que medida a dislexia está retratada nas políticas públicas de inclusão? De que forma a tecnologia móvel pode contribuir para a aquisição da leitura e escrita de crianças disléxicas? Para responder a essas questões desenvolvemos uma pesquisa qualitativa em duas etapas. Na primeira, realizamos um levantamento bibliográfico a partir de autores como: Navas et al. (2017), Reis (2006, 2013), Maia (2016), Prensky (2012); e, documentos que contribuíram no que se refere ao assunto tratado neste estudo, como: Unesco (1990, 1994, 2014 e 2016), entre outros. Na segunda etapa da pesquisa, um estudo de caráter exploratório, visando a caracterizar o Aplicativo móvel "Silabando" (disponível para download gratuito na Google Play) para analisar suas possibilidades de auxílio na aquisição da leitura e escrita de crianças disléxicas.

Fizemos uso de uma abordagem de pesquisa qualitativa. Essa pesquisa privilegia o uso do texto "como material empírico (ao invés de números), parte da noção da construção social das realidades em estudo, está interessada nas perspectivas dos participantes, em suas práticas do dia a dia e em seu conhecimento cotidiano em relação ao estudo" (FLICK, 2009, p.16).

Desse modo, organizamos o presente texto em duas seções: na primeira apresentamos concepções e intersecções sobre dislexia, políticas públicas de inclusão e tecnologia móvel; na segunda compartilhamos resultados da análise do Aplicativo móvel 'Silabando' a qual dividimos em dois tópicos: no primeiro, fazemos a caracterização do aplicativo bem como suas funcionalidades. No segundo, discutimos sobre as possibilidades de auxílio desse aplicativo móvel na aquisição da leitura e escrita de crianças disléxicas.

\section{CONCEPÇÕES E INTERSECÇÕES SOBRE O TRIPÉ: DISLEXIA, POLÍTICAS PÚBLICAS DE INCLUSÃO E TECNOLOGIA MÓVEL}

Conforme Maia (2016, p. 85), “a dislexia é apresentada em várias formas de linguagem, frequentemente incluídos problemas de leitura, em aquisição e capacidade de escrever e soletrar". O Instituto $\mathrm{ABCD}^{2}$ (2018) apresenta a dislexia como uma condição neurobiológica ligada à habilidade de aprendizagem da leitura e da escrita. Essa, apesar de se tornar mais evidente quando a criança inicia o período escolar, ocorre desde os primeiros anos de vida, pois é causada por alterações na formação neurológica, que podem estar relacionadas à origem genética.

2 Organização da sociedade civil de interesse público (OSCIP) que se dedica, desde 2009, a gerar, promover e disseminar projetos com impacto positivo na vida de brasileiros com dislexia e outros transtornos específicos de aprendizagem. 
Grande parte dos docentes, quando percebem crianças invertendo letras ou escrevendo de forma espelhada (fora da ordem - da esquerda para a direita o aluno escreve da direita para a esquerda e as letras também aparecem viradas ao contrário), pensa logo que é um problema visual. Neste caso, conforme Maia (2016), não se trata de um problema relacionado à visão das letras na direção errada e existem fortes indícios de que se trata de um distúrbio de linguagem, chamado dislexia.

Para Maia (2016, p. 85), “apesar de instrução convencional, adequada inteligência, oportunidades socioculturais, sem distúrbios cognitivos e sensoriais fundamentais, a criança falha no processo de aquisição da linguagem", ou seja, a condição do distúrbio, "compromete a memória operacional fonológica" das crianças disléxicas (BARBOSA, et al., 2017, p.69).

Assim, a pessoa disléxica não tem deficiência intelectual e não há sinais de distúrbios sensoriais, como pouca visão ou perda auditiva. Apresenta apenas uma insuficiência com o processamento fonológico, ou seja, dificuldades acentuadas na decodificação das palavras (MAIA, 2016). Nesse sentido, de acordo com o autor, se houver intervenção o quanto antes e de forma intencional, as crianças podem apresentar desenvolvimento linguístico típico para a idade.

Para Navas et al. (2017), grande parte das crianças disléxicas que estão nas escolas não está sendo atendida em suas necessidades educacionais especiais. Isso acontece pelo fato de receberem um diagnóstico tardio, pois, conforme Barbosa et al.(2017, p. 69), "os professores têm dificuldade na identificação real do problema, de suas manifestações e das formas como intervir e prevenir".

Nesse caso, torna-se fundamental que o professor identifique a dislexia para não rotular a criança de preguiçosa ou desinteressada; ao contrário, faz-se necessário estabelecer práticas pedagógicas que atendam as crianças em suas dificuldades de consciência fonológica. Para tanto, é relevante que os docentes superem práticas conservadoras que ainda enfatizam exercícios de alfabetização obsoletos, sem atratividade, considerados falhos no processo de aquisição da leitura e escrita.

\footnotetext{
Além disso, em razão da preponderância de métodos globais de alfabetização, a quantidade de instrução fonológica e ensino de correlações entre grafema e fonema tem sido pouca (a palavra "falha" seria melhor empregada aqui) em nossas escolas, trazendo prejuízos ao letramento de nossas criança. (MAIA, 2016, p.86).
}

A partir das considerações do autor, percebemos certo despreparo da escola para atender adequadamente o público com dislexia. É preciso entender que a criança disléxica não deixará de apresentar essa condição, mas se houver 
apoios, abordagens de ensino e estratégias específicas para ajudá-la a superar seus desafios na aquisição da leitura e escrita, ela se sentirá incluída e capaz, bem como conseguirá alcançar uma aprendizagem significativa.

Sinais de dislexia podem ser identificados pelo professor em diferentes idades e fases de escolarização. Na pré-escola, por exemplo, há sinais como: dificuldade em reconhecer duas palavras que rimam; a criança se sente incomodada com a remoção do som inicial de uma palavra e apresenta dificuldades em aprender novas palavras; dificuldade em reconhecer letras e combiná-las com sons; retirar o som do meio de uma palavra ou misturar vários sons para formar uma palavra; muitas vezes não consegue reconhecer palavras comuns e esquece rapidamente como soletrar muitas das palavras que ouve e conhece (SANCHEZ, 2014).

Já no ensino fundamental, os sinais são percebidos quando a criança apresenta diversos erros de ortografia; frequente releitura de frases e passagens; leitura em um nível inferior ao de sua fala; muitas vezes deixa de ler pequenas palavras ao ler em vOz alta; resistência à leitura em voz alta ou para si mesma (CUNHA; CAPELLINI, 2009).

Ao considerar os déficits reais dos discentes com dislexia, vale ressaltar que, assim como quaisquer outros discentes, os disléxicos, possuem o direito de aprendizagem na escola regular, sobretudo ao considerarmos que a inclusão é para todos. Em relação à inclusão, assumimos a perspectiva de Reis (2006), ao pontuar que

A inclusão propõe um único sistema educacional de qualidade para todos os alunos, com ou sem deficiência e com ou sem tipos de condição atípica. É a valorização do ser humano e aceitação das diferenças individuais como um atributo e não como um obstáculo e todas as pessoas devem ser incluídas, sem exceção, para que possam desenvolver-se e exercer plenamente sua cidadania (REIS, 2006, p. 41, grifo da autora).

De acordo com esta autora, um sistema educacional só se tornará de qualidade quando aceitar o ser humano e suas diferenças individuais como um atributo e não como obstáculo. Assim, uma escola para todos, exige contextos educacionais capazes de atender a todos, independente de suas necessidades físicas/sensoriais, neuropsicosociais, dentre outras características. Isso demanda, além de políticas públicas, investimentos numa educação de qualidade. "Cabe ao Estado, nessas políticas, o papel de possibilitar a todos o ingresso e a permanência na educação escolar" (NADER, 2007, p. 413). 
Diante deste papel, ganham destaque dois marcos internacionais, que influenciaram e influenciam a formulação de leis e políticas de inclusão: a Declaração Mundial sobre Educação para $\operatorname{Todos}^{3}$ (1990) e a Declaração de Salamanca ${ }^{4}$ (1994).

A primeira ressalta a necessidade de se reunirem esforços na luta pelo acesso às necessidades básicas de aprendizagem de todos os cidadãos, sejam eles crianças, jovens ou adultos. É composta por dez artigos, os quais consideram que as pessoas com necessidades educacionais especiais devem ser vistas como cidadãos 'comuns' bem como 'peculiares'.

Conforme aponta o art. $3^{\circ}$, são considerados comuns ao permitir que o acesso à educação com equidade de forma universalizada seja direito de todos, enquanto no art. $5^{\circ}$ entende-se que são peculiares ao evidenciar que é necessário garantir igualdade ao acesso à educação de modo integrante do processo educativo, independente do grau de necessidade que possuir.

\begin{abstract}
Seu caráter otimista traduz um avanço em relação à concepção de educação, ao considerá-la um direito de todos e, da mesma forma, ao colocar sob responsabilidade do Estado a garantia de atendimento educacional extensivo às pessoas deficientes na rede regular de ensino. Esse cenário fortalece ainda mais o princípio inclusivo, que, garantido e legitimado por leis, passa a ser foco de desdobramentos, com os expressivos movimentos a favor da diversidade social e educacional ocorridos em diferentes países na década de 1990 e adentrando as décadas posteriores (REIS, 2013, p.116).
\end{abstract}

Compreendemos que a Declaração Mundial Sobre Educação para Todos fortaleceu a inclusão e representou um grande avanço no atendimento educacional às pessoas com necessidades educacionais especiais. Trouxe em seu bojo princípios básicos de resgate da valorização das diferenças que se tornaram o pilar da política educacional de diversidade. Conforme esse documento, cada pessoa, seja ela criança, jovem ou adulto deve ter acesso educacional, independente das condições de idade, gênero, situação social, crença, religião ou quaisquer características físicas, sensoriais ou psicológicas.

Alinhada a essa primeira, surge, em 1994, a Declaração de Salamanca. Nessa declaração foram lançados os princípios fundamentais da Educação Inclusiva, com foco principal na Educação Especial, em todos os países. O documento expressa como princípios norteadores o reconhecimento das diferenças, o atendimento às necessidades de cada um, a promoção da aprendizagem, o reconhecimento da

\footnotetext{
3 Resultado da Conferência Mundial sobre Educação para Todos, maior movimento pela educação inclusiva, que reuniu educadores de vários países, realizada em Jomtien, Tailândia, de 5 a 9 de março de 1990.

4 Resultado da Conferência Mundial sobre Necessidades Educativas Especiais, realizada em junho de 1994, na cidade de Salamanca/Espanha.
} 
importância de uma "instituição para todos" e a formação de professores. Por meio desses princípios fica explícita

A afirmação dos direitos à educação e oportunidades de manter um nível de aprendizagem que respeite as características próprias de cada aluno, com base em planejamento e programas que contemplem as diferenças de cada um, a fim de que se construa uma sociedade solidária, capaz de combater qualquer tipo de atitude discriminatória (REIS, 2013, p. 118).

Percebemos nas considerações da autora a reafirmação do compromisso dessa declaração com uma educação de qualidade para todos dentro do sistema regular de ensino, bem como a evidência de desafios desses sistemas no que diz respeito a formas de ensinar satisfatoriamente, incluindo os que possuem desvantagens ou dificuldades, seja de ordem física, mental ou social. Nesse sentido, é nítido que os discentes com dislexia estão inseridos nesse público, pois possuem necessidades específicas que necessitam de recursos também específicos para se desenvolverem. Assim sendo, também necessitam de um olhar atento do poder público no que se refere à implementação de políticas públicas que garantam sua inclusão.

Consideramos que "as políticas (e políticas educacionais) são respostas do Estado (atos do Estado) para buscar atender problemas existentes e demandas da população" (MAINARDES, 2018, p. 188). Desse modo, para alcançar os pressupostos estabelecidos nas políticas educacionais expressas nas duas declarações supracitadas, o Estado não pode eximir-se de seu papel de possibilitar a todos o ingresso e a permanência na escola de forma a garantir a inclusão escolar.

A par disso, este estudo sinaliza uma crítica ao Estado no que se refere às políticas públicas de educação com foco na inclusão, pois mesmo diante dos fundamentos legais presentes nos dois documentos internacionais aqui citados dos quais o Brasil é signatário -a dislexia ainda está ausente na política nacional de nosso país. De acordo com os estudos de Estill (2016), diferentemente da 
Inglaterra ${ }^{5}$, Estados Unidos ${ }^{6}$ e Espanha ${ }^{7}$, o Brasil não contempla a dislexia em sua Política Nacional de Educação Especial numa Perspectiva Inclusiva, em vigência desde 2008. Essa política tem como público-alvo, apenas "alunos com deficiência, transtornos globais de desenvolvimento e altas habilidades/superdotação" (BRASIL, 2008, p. 15).

O mesmo aconteceu com o Plano Nacional de Educação (PNE) com vigência de 2014 a 2024. A meta "4" que contempla a Educação Especial numa Perspectiva Inclusiva não abarca o atendimento educacional especializado ao público da dislexia. Essa meta traz dois grandes objetivos em sua proposição: o primeiro diz respeito à universalização do acesso à Educação Básica e ao atendimento educacional especializado para a população de 4 a 17 anos com deficiências, transtornos globais do desenvolvimento (TGD) e altas habilidades ou superdotação; o segundo objetivo preconiza que esse atendimento educacional se dê preferencialmente na escola regular (BRASIL, 2015).

Nesse sentido, percebemos que o PNE 2014-2024 valida a Política Nacional de Educação Especial numa Perspectiva Inclusiva (2008) ao ausentar os disléxicos das diretrizes específicas estabelecidas nessas políticas, como o atendimento educacional especializado e a formação de professores para as necessidades específicas da dislexia.

Assim, poderíamos enunciar essa situação como prática de exclusão educacional? Se considerarmos a existência de documentos normativo-legais em âmbito nacional que resguardam o direito de aprendizagem ao público com dislexia, diríamos que sim. Diríamos, ainda, que isso reverbera numa escola e em profissionais sem a mínima condição de atender com qualidade as necessidades específicas desses discentes. Esses profissionais, muitas vezes, percebem-se solitários e despreparados para a realização do trabalho; e, sabem da necessidade de formação para isso.

Diante desse cenário, a Associação Nacional de Dislexia (AND/RJ) juntamente com a Associação de Pais de Disléxicos (APAD) promoveram intensos movimentos. De acordo com Estill (2016), após o encaminhamento de propostas ao MEC para desenvolver um projeto de criação de diretrizes gerais para inclusão

\footnotetext{
5 Resolução "Special Educational Needs and Disability Act (2001)" declara que as escolas não podem discriminar os alunos com deficiências (sendo a definição de deficiência ampla e incluindo a dislexia).

6 Lei Federal "Individuals with Disabilities Education Act - IDEA (2004)", determina como os estados e organizações públicas devem promover ações de intervenção precoce, e atendimento especializado para crianças com necessidades especiais, incluindo deficiência mental, auditiva, visual e física, distúrbios emocionais, autismo, sequelas de traumatismo craniano, distúrbios de fala e de linguagem, TDAH e Transtornos específicos de aprendizagem (dislexia, discalculia, disortografia).
}

7 Lei Organica de Educación 2/2006, incorpora em uma resolução de âmbito nacional o termo "Distúrbios Específicos de Aprendizagem", reconhecendo as necessidades educacionais do público com dislexia. 
da dislexia na política educacional inclusiva, o Ministério da Educação criou um grupo de trabalho visando à elaboração de diretrizes gerais para a inserção da dislexia e do transtorno do déficit de atenção com hiperatividade (TDAH) nas políticas públicas de inclusão escolar.

O documento produzido por esse grupo, intitulado 'Diretrizes Gerais para Inclusão dos Transtornos Específicos' foi concluído e entregue à Secretaria de Educação Básica (SEB) para leitura, aprovação e homologação em dezembro de 2008, mas, até o momento, ainda se encontra engavetado no MEC (ESTILL, 2016). Há também um Projeto de Lei no $7081 / 2010$, que obriga o Poder Público a manter um programa de acompanhamento integral aos disléxicos e aos estudantes com transtorno do déficit de atenção com hiperatividade (TDAH) da Educação Básica da rede pública e privada, mas ainda não foi aprovado, e encontra-se atualmente em tramitação no Senado Federal. Dessa forma, validamos a iniciativa da Associação Nacional de Dislexia (AND) e corroboramos seus pressupostos no sentido de reivindicar ao Estado Brasileiro que a dislexia seja incluída nas políticas públicas nacionais numa perspectiva inclusiva como em outros países já mencionados. Isso porque, ao considerarem os movimentos internacionais de educação para todos, incluem os disléxicos em suas políticas públicas de inclusão.

Portanto, consideramos primordial o papel do estado na garantida de igualdade de condições aos discentes com dislexia no que se refere ao acesso e permanência na escola conforme preconiza a Constituição Federal de 1988. E isso pode ocorrer por meio da implementação de políticas públicas que contemplem adaptações específicas, formação continuada aos docentes e normatização do atendimento educacional especializado também para o público da dislexia, além de recursos materiais adaptados e/ou específicos para uma escola que já vivencia grandes desafios diante dos princípios da inclusão.

Uma política pública nesse patamar que estamos defendendo adota ações que podem possibilitar acessibilidade na aprendizagem para discentes com dislexia. Tais ações vão desde a formação continuada para os professores, passando pela disponibilização de recursos materiais simples, até aos recursos mediados pelas tecnologias digitais de informação e comunicação, aqui com destaque para a tecnologia móvel em smartphones e tablets, um dos assuntos deste artigo.

Estas tecnologias, fruto do desenvolvimento tecnológico alcançado pelo ser humano, têm um papel fundamental no âmbito da inovação sendo sua principal marca, a tecnologia digital. De acordo com a Unesco,

As tecnologias móveis estão em constante evolução: a diversidade de aparelhos atualmente no mercado é imensa, e inclui, em linhas gerais, telefones celulares, tablets, leitores de livros digitais (e-readers), aparelhos portáteis de áudio e consoles manuais de videogames (UNESCO, 2014, p. 8, grifo do documento). 
Diante disso, notamos a marcação de um novo tempo, a "era digital". Essas tecnologias possibilitam a ubiquidade, ou seja, o acesso sem fio à informação da Web ou de qualquer outro sistema, praticamente de qualquer lugar, a qualquer momento. Por serem altamente portáteis e relativamente acessíveis ampliam o potencial e a possibilidade da aprendizagem personalizada.

Em relação ao uso dessa tecnologia, mais especificamente de celulares, de acordo com a Unesco $(2014$, p. 9) "existem mais de 3,2 bilhões de assinantes de telefonia celular em todo o mundo, tornando o telefone celular a TIC interativa mais amplamente usada no planeta". Observamos que os dispositivos móveis estão cada vez mais presentes, mesmo entre as classes com menor poder aquisitivo, propiciando um cenário favorável para seu uso no ambiente escolar (ALLAN, 2013).

Um dos maiores desafios que emerge para o professor do século XXI é entender as inovações desta era e incorporá-las às práticas pedagógicas em um espaço de aprendizagem formado por alunos interativos e conectados em decorrência das tecnologias móveis.

Com a evolução das tecnologias móveis, configura-se, segundo Moura (2010), um novo paradigma educacional denominado mobile learningou m-learning (aprendizagem móvel). “A aprendizagem móvel envolve o uso de tecnologias móveis, isoladamente ou em combinação com outras tecnologias de informação e comunicação (TIC), a fim de permitir a aprendizagem a qualquer hora e em qualquer lugar" (UNESCO, 2014, p. 8, grifo no original).

A aprendizagem móvel apresenta atributos exclusivos se comparada à aprendizagem convencional: ela é pessoal, portátil, colaborativa, interativa, contextual e situada; ela enfatiza a 'aprendizagem instantânea' já que a instrução pode ocorrer em qualquer lugar e a qualquer momento. Além disso, ela pode servir de apoio às aprendizagens formal e informal, tendo assim um enorme potencial para transformar a forma de ensinar e aprender (UNESCO, 2014).

A escola não pode ficar alheia às transformações que emergem em virtude da presença maciça das tecnologias digitais de informação e comunicação. Desse modo, é fundamental a redefinição de práticas educacionais que contemplem a "cibercultura"8 e seus dispositivos (PRENSKY, 2012). Para Freitas e Reis,

A integração da tecnologia na educação, principalmente a digital, torna-se importante pela inegável presença das TDIC nas interações sociais, portanto sua inserção nas atividades de ensino se torna uma necessidade, pois permite aos envolvidos em tal processo, acesso ilimitado ao conhecimento e um aprendizado significativo (FREITAS; REIS, 2018, p.3). valores que se desenvolvem juntamente com o ciberespaço” (LÉVY, 1999, p. 17). 
De acordo com as considerações dessas autoras, a integração da tecnologia digital na educação é fundamental, pois, além de aproximar de sua realidade o aprendiz, atenuando o fosso existente entre a escola e a sociedade da informação, permite-lhe o acesso ao conhecimento por meio de uma aprendizagem móvel, construída a qualquer dia, em qualquer hora e em qualquer lugar.

Isso demanda uma mudança na função do professor, uma vez que este deixa de ser apenas um provedor direto do conhecimento, movimentando-se a um "animador da inteligência coletiva de seu grupo de alunos" (LÉVY, 1999, p. 160). A mudança necessária no modelo pedagógico é que o professor deixe de ser um 'expositor' para ser um 'orientador', possibilitando que os estudantes aprendam por si próprios e uns com os outros (MORAN, 2015). Dessa forma, torna-se primordial que "os educadores entendam essas inovações para que possam influenciar o seu desenvolvimento, ao invés de simplesmente reagir a elas" (UNESCO, 2014, p. 25).

O uso da tecnologia móvel na educação pode ser potencializado a partir de aplicativos adequados às necessidades dos envolvidos no processo ensinoaprendizagem. Hoje, dispomos gratuitamente de uma ampla gama de aplicativos que podem ser utilizados em sala de aula de acordo com os objetivos a serem alcançados. São vários jogos digitais com possibilidades de trabalho pedagógico.

Acreditamos que alunos com algum tipo de dificuldade cognitiva, que apresentam menor rendimento, podem ser beneficiados com o uso de tecnologias que atendam a seus próprios ritmos de aprendizagem, inclusive, alunos que outrora não eram atendidos em suas necessidades, como os disléxicos, e agora podem ser (GROSSI; FERNANDES, 2014).

Sendo assim, na próxima seção, apresentamos um desses aplicativos que oferecem possibilidade de aprendizagem móvel para crianças disléxicas de oito anos de idade, em relação ao processo de aquisição da leitura e da escrita.

\section{ANÁLISE DO APLICATIVO MÓVEL 'SILABANDO'}

Nesta seção do trabalho, apresentamos os resultados da análise do Aplicativo móvel 'Silabando' em dois tópicos. Primeiro realizamos uma caracterização do aplicativo bem como a apresentação de suas funcionalidades. Em seguida, discutimos as possibilidades de auxílio desse aplicativo móvel na aquisição da leitura e escrita de crianças disléxicas. 


\section{CARACTERIZAÇÃO E FUNCIONALIDADES}

O aplicativo móvel "Silabando" está disponível para download em smartphones e tablets no idioma Português Brasileiro de forma gratuita na Google Play $^{9}$ e se caracteriza como um jogo digital, totalmente educativo e desenvolvido especificamente para crianças de até oito anos de idade que estão em processo de alfabetização. Em média, são crianças que estão entre o $1^{\circ}$ e $3^{\circ}$ Ano do Ensino Fundamental.

Foi desenvolvido pela empresa Apps Bergman ${ }^{10}$, passou por atualização em 8 de maio de 2018, e, em sua versão atual, requer Android 4.0.3 ou superior e um espaço de $24 \mathrm{MB}$. Tem como objetivo principal a aprendizagem da leitura e escrita em um sistema de alta resolução que agrega letras, sílabas, palavras, imagens, com suporte de voz e feedback que estimula as crianças a sentir prazer na realização das atividades.

Para facilitar o entendimento das suas funcionalidades, apresentamos, na figura 1, a marcação de cada atividade e, logo abaixo, suas descrições.

\section{Figura 1 - Tela inicial de atividades com sílabas simples}

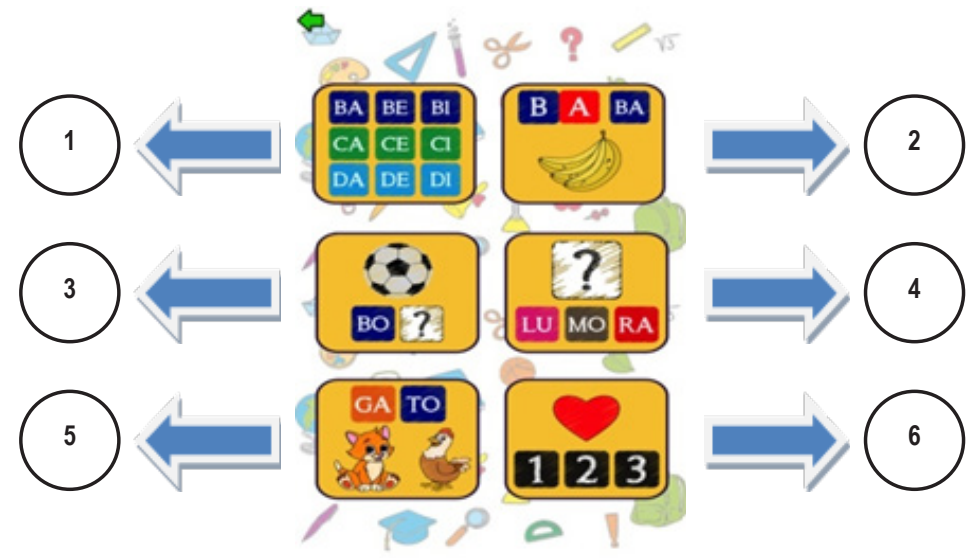

Fonte: Print screen da tela do aplicativo realizado pelas autoras, em 10 de dezembro de 2018

\footnotetext{
9 Disponível em: https://play.google.com/store/apps/details?id=com.appsbergman silabando\&hl=pt_BR Acesso em: 01 de set. de 2018.

10 Rua L. de Azevedo, 1793, Belo Horizonte/MG 30421-428 Brasil. E-mail: contato@appsbergman. com
} 
No retângulo de número 1 , a atividade refere-se ao conhecimento do alfabeto e formação de sílabas conforme a escolha da criança; no 2, formar sílabas em um contexto concreto com suporte de imagens; no 3, a atividade consiste em completar a palavra com a sílaba correta; no 4, encontrar a sílaba correspondente ao som; no 5, ler as sílabas e clicar na imagem correspondente; e, no 6, relacionar a quantidade de sílabas das palavras correspondentes às imagens apresentadas. Todas as atividades possuem guia de voz e feedback.

Para melhor compreensão, apresentamos na próxima ilustração, a exemplificação da atividade de número 3 , mencionada anteriormente.

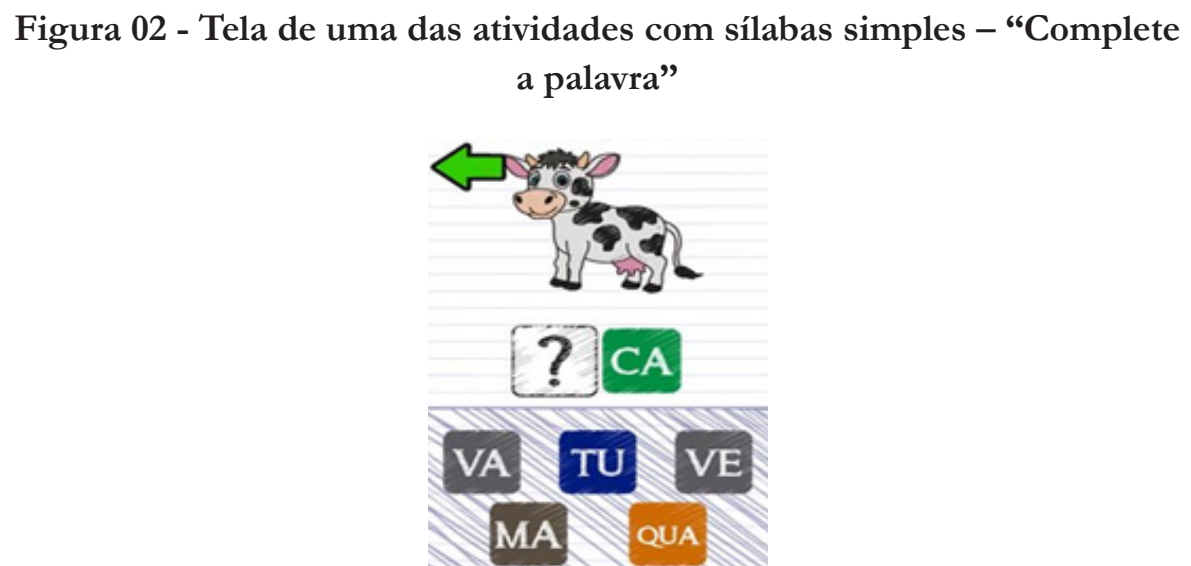

Fonte: Print screen da tela do aplicativo realizado pelas autoras, em 10 de dezembro de 2018

Esse aplicativo móvel oferece oportunidades de vivenciar 6 (seis) modalidades de atividades e cada uma delas apresenta em média 40 diferentes possibilidades de exploração. Em relação às imagens anteriores, a atividade consiste em formar palavras com sílabas simples e a possibilidade explorada é completar a palavra relacionada à imagem e ao som. No caso do exemplo apresentado, a criança tem cinco sílabas para definir a correspondente da palavra "vaca". É importante destacar que em todas as atividades, a criança tem ajuda de um guia de voz. Nesse guia, a cada letra, sílaba ou palavra clicada emite-se o seu som, que se repete quantas vezes a criança clicar, ajudando na compreensão. Os mesmos procedimentos se repetem para as atividades com as sílabas complexas. 


\section{POSSIBILIDADES PEDAGÓGICAS INCLUSIVAS PARA CRIANÇAS DISLÉXICAS PELA INTERFACE DO APLICATIVO MÓVEL 'SILABANDO'}

Ao explorar o Aplicativo móvel 'Silabando', verificamos que ele tem um display divertido, simples e interativo que aumenta a vontade de aprender. Vimos, ainda, que possibilita trabalhar: sílabas simples e complexas (com o uso de letras maiúsculas, minúsculas e cursivas); exemplo de palavra e imagem em cada sílaba; atividades divertidas para memorização e pronúncia de cada sílaba.

O dispositivo disponibiliza diversas atividades que utilizam os seguintes recursos: apresentação das sílabas; montagem de sílabas e ilustração; completar a palavra com a sílaba correta; escutar a sílaba e tentar descobrir qual é agrafia correspondente ao som; tentar ler a palavra separada em sílabas e clicar na imagem correspondente, o número de sílabas que cada palavra tem. Isso ocorre tanto trabalhando as sílabas simples quanto as complexas.

Em Carlin (2015) e em Santos e Costa (2014) identificamos alguns requisitos que evidenciam estratégias de aprendizagem desenvolvidas em um programa de consciência fonológica para crianças disléxicas. Esses requisitos pautam parte da análise do aplicativo que selecionamos e que estão identificados no quadro abaixo.

\section{Quadro 01 - Análise do aplicativo "Silabando"}

\begin{tabular}{|c|c|c|c|c|c|}
\hline Qt. & REQUISITOS & $\mathrm{A}$ & $\mathrm{N}$ & $\mathrm{AP}$ & $\mathrm{NA}$ \\
\hline 01 & Associar letras aos seus respectivos sons & $\mathrm{x}$ & & & \\
\hline 02 & $\begin{array}{c}\text { Distinguir uma sílaba contendo um fonema alvo dentre } \\
\text { diversas outras sílabas. }\end{array}$ & $\mathrm{x}$ & & & \\
\hline 03 & $\begin{array}{c}\text { Identificar se pares de palavras apresentam um som em } \\
\text { comum. }\end{array}$ & & $\mathrm{x}$ & & \\
\hline 04 & $\begin{array}{c}\text { Diferenciar uma palavra com som diferente dentre diversas } \\
\text { outras palavras com sons semelhantes. }\end{array}$ & $\mathrm{x}$ & & & \\
\hline 05 & $\begin{array}{c}\text { Emitir o som correspondente aos grafemas apresentados e } \\
\text { as sílabas formadas pela junção de grafemas. }\end{array}$ & $\mathrm{x}$ & & & \\
\hline 06 & Identificar um fonema alvo contido dentro de uma palavra. & $\mathrm{x}$ & & & \\
\hline 07 & Identificar todos os fonemas contidos em uma palavra. & $\mathrm{x}$ & & & \\
\hline 08 & $\begin{array}{c}\text { Identificar qual a nova palavra formada quando se retira um } \\
\text { fonema desta palavra. }\end{array}$ & & $\mathrm{x}$ & & \\
\hline 09 & Fornece feedback ao aluno sobre seu desempenho & $\mathrm{x}$ & & & \\
\hline \multicolumn{5}{|c|}{ Legenda: A = Atendido $\mathrm{N}=$ Não Atendido AP = Atendido Parcialmente NA = Não se Aplica } & \\
\hline
\end{tabular}

Fonte: as autoras, com base em: Carlin (2015) e Santos; Costa (2014). 
Notamos que o aplicativo analisado não dispõe de dois requisitos, a saber, "Identificar se pares de palavras apresentam um som em comum" e "Identificar qual a nova palavra formada quando se retira um fonema dessa palavra". Contudo, isso não diminui a qualidade da utilização do aplicativo com crianças disléxicas em virtude de outras vantagens que ele apresenta.

Esse aplicativo oferece maneiras de aprender sílabas simples ou complexas de forma atrativa, mostrando as imagens correspondentes a cada palavra formada. As letras possuem um tamanho maior para uma melhor visualização e é destacada com cores; cada letra tem uma cor ou mesmo cada sílaba. Apresenta apoio com guia de voz - ao clicar, emite-se o som da letra, sílaba ou palavra, além de se repetir quantas vezes a criança clicar, ajudando na memorização.

Percebemos a possibilidade de estímulo à linguagem fonética e linguagem silábica com reforço para a construção da consciência fonológica pelas crianças disléxicas (BARBOSA, et al., 2017).

Dentre as vantagens, também cabe mencionar que o aplicativo móvel 'Silabando' é um aplicativo educativo que pode ser utilizado com todas as crianças de uma mesma turma, o que contribui para uma atuação na perspectiva e princípios da inclusão, em que, "todas as pessoas devem ser incluídas, sem exceção, para que possam desenvolver-se e exercer plenamente sua cidadania” (REIS, 2006, p. 41).

$\mathrm{O}$ aplicativo auxilia quem tem dificuldade de relacionar o reconhecimento e interpretação dos sons às palavras e sílabas, ordenar e escrever corretamente as letras, além de memorizar sons e sílabas e estimular a coordenação motora, o que, para as crianças disléxicas é fundamental. Além do mais, o esquema de leitura estruturado, que envolve repetição e introduz novas palavras lentamente, permite que a criança disléxica desenvolva confiança e autoestima ao ler (SANCHEZ, 2014).

É importante esclarecer que o destaque com cores fortes do aplicativo e o apoio com guia de voz também pode estimular a percepção da memória auditiva, visual e sequencial, a coordenação visomotora, a ativação dos dois hemisférios cerebrais (imagens e texto) (BARBOSA, et al., 2017) e, assim, oferecer à criança disléxica a oportunidade de construção do seu conhecimento, facilitando a aquisição da leitura e escrita.

Nesse sentido, a memória operacional fonológica, comprometida nas crianças disléxicas (BARBOSA, et al., 2017),pode ser facilitada com a utilização do aplicativo móvel 'Silabando', uma vez que ele apresenta em todas as suas atividades um guia sonoro que pode ajudar na correlação fonemas/grafemas.

Vale salientar que em uma média de zero a cinco pontos, o aplicativo está atualmente avaliado com 4,6 pontos, na Google Play e 3,8 pontos na Apple Store, médias consideráveis, tendo em vista a pontuação máxima. 
Consideramos que o aplicativo alia ludicidade, atratividade, aprendizagem e demonstra ser eficiente porque faz uso de técnicas de aprendizagem interativas. Entre essas técnicas, Prensky (2012) destaca algumas como a possibilidade de aprender na prática e com os erros; a devolutiva imediata com feedback para a criança; aprendizagem guiada por meta, descoberta, pergunta; aprendizagem fundamentada em tarefas; aprendizagem contextualizada, construtivista, roleplaying; treinamento; e, além do mais,seleção a partir de objetos de aprendizagem e instrução inteligente. “Ao contrário do que se pensa a aprendizagem móvel não aumenta o isolamento, mas sim oferece às pessoas, mais oportunidades para cultivar habilidades complexas exigidas para se trabalhar de forma produtiva" (UNESCO, 2014, p. 18).

Nesse sentido, a tecnologia presente no aplicativo móvel 'Silabando', oferece possibilidades pedagógicas de incluir a criança com dislexia de forma a amenizar suas dificuldades relacionadas à leitura e a escrita.

A prática do seu uso se apresenta relevante por apresentar possibilidades de mediar, para a criança disléxica, um ensino lúdico e atrativo, de qualidade e, assim, promover a educação inclusiva. Além disso, o professor não necessita de conhecimento teórico para seu uso em sala, pois é intuitivo e de fácil manuseio.

A aprendizagem fundamentada em jogos digitais é produtiva, pois está de acordo com o estilo de aprendizagem das crianças dos dias atuais, consideradas nativos digitais. Ademais, é motivadora, lúdica e versátil e ainda, oportuniza sua adaptação a quase todas as disciplinas e habilidades a serem desenvolvidas, sendo muito produtiva se for utilizada com intencionalidade (PRENSKY, 2012).

\section{CONSIDERAÇÕES FINAIS}

Diante do estudo realizado, notamos que a dislexia é caracterizada por um baixo desempenho na precisão e na velocidade da leitura e escrita, que persiste apesar do bom nível intelectual, da ausência de déficits sensoriais e das oportunidades de aprendizagem recebidas. Por ser uma condição associada à constituição cerebral, a dislexia não tem cura, mas, a partir da identificação e das intervenções nas dificuldades, é possível alcançar um desenvolvimento adequado nas habilidades escolares e na vida, de um modo geral.

Vimos que no Brasil há uma morosidade no que se refere às políticas públicas de inclusão que contemplem a dislexia. Tanto na Política Nacional de Educação Especial na Perspectiva Inclusiva (2008) quanto no Plano Nacional de Educação 2014-2024, a dislexia ainda se encontra ausente, fato que pode justificar 
a falta de investimentos na escola e na formação docente para as especificidades desse público, desafiando-a em seu processo de ensino e aprendizagem relacionado às crianças disléxicas.

Consideramos que as inovações tecnológicas em toda a sua amplitude dispõem de uma infinidade de ferramentas virtuais e online que são de grande importância para o trabalho de inclusão, tanto na área da dislexia como também em outras dificuldades e deficiências. Contudo, torna-se fundamental a efetivação de políticas públicas de inclusão que contemplem o atendimento às necessidades específicas dos discentes disléxicos. É importante, ainda, que essas políticas respaldem o redimensionamento das práticas pedagógicas e estabeleçam diretrizes para a formação continuada dos docentes, passando pela disponibilização de recursos materiais simples até aos recursos mediados pelas novas tecnologias de informação e comunicação.

Diante disto, ressaltamos que, para lidar com a criança que tem dislexia, o educador necessita ir além das áreas conteudistas -habituais de formação conhecendo e desenvolvendo um conjunto de práticas que permitam às crianças alcançarem o sucesso, isto é, atingir o limite superior das suas capacidades, o que reverbera a necessidade de formação continuada para esse professor.

Nesse sentido, notamos que a tríade apresentada neste trabalho: políticas públicas de inclusão, dislexia e tecnologia móvel, pode ser implementada mediante o papel do estado de garantir uma educação de qualidade para todos.

Foi pensando nisso que apresentamos, neste artigo, possibilidades pedagógicas inclusivas pela interface de um aplicativo disponível na Google Play, chamado 'Silabando'. Ao explorar e analisar esse aplicativo percebemos que ele apresenta possibilidades de auxiliar a criança disléxica em seu processo de aquisição da leitura e escrita. Apresenta ainda, várias vantagens para o auxílio na consciência fonológica, incluindo o desenvolvimento das habilidades de separação silábica, ortografia, reconhecimento e memorização de sons e coordenação motora fina.

\section{REFERENCIAS}

ALLAN, Luciana Maria. A proibição do celular nas escolas faz sentido? Disponível em: <http://porvir.org/proibicao-celular-nas-escolas-faz-sentido/20130730/>. Acesso em: 03 maio 2018.

BARBOSA, Thaís. et al.A Experiência do NANI/CPN no Atendimento de Crianças e Adolescentes com Transtornos de Aprendizagem. In: NAVAS, Ana Luiza et. al. Guia de boas práticas: do diagnóstico à intervenção de pessoas com transtornos específicos de aprendizagem. São Paulo: Instituto ABCD, 2017. 
BRASIL. Constituição da República Federativa do Brasil. Brasília, DF: Senado Federal: Centro Gráfico, 1988. 292 p.

BRASIL. Diretrizes Nacionais para a Educação Especial na Educação Básica. Brasília: Ministério da Educação, Seesp, 2001.

BRASIL. Ministério da Educação. Secretaria de Educação Especial. Política Nacional de Educação Especial na Perspectiva da Educação Inclusiva. Brasília: Ministério da Educação, Seesp, 2008.

BRASIL. MEC. Instituto Nacional de Estudos e Pesquisas Educacionais Anísio Teixeira. Plano Nacional de Educação PNE 2014-2024: Linha de Base. Brasília, DF: Inep, 2015.

CAMINHA, Vera Lúcia; HUGUENIN, Julliane Yoneda; ASSIS, Lúcia Maria de; ALVES, Priscila Pires. (Org.). Autismo: vivências e caminhos. $1^{a}$ ed. São Paulo: Blucher, 2016.

CARLIN, Cássio Angelo. Ferramenta de auxílio às crianças com dislexia para dispositivos móveis. Santa Cruz do Sul: Repositório Institucional UNISC, 2015. Disponível em: $<$ https://repositorio.unisc.br/jspui/bitstream/11624/1033/1/ C\%C3\%A1ssio\%20Angelo\%20Carlin.pdf> Acesso em: 01de set. de 2018.

CARVALHO, Rosita Edler. Removendo barreiras para a aprendizagem. Rio de Janeiro: WVA, 2000.

CUNHA, Vera Lúcia Orlandi.; CAPELLINI, Simone Aparecida. Desempenho de escolares de $1^{a}$ a $4^{a}$ série do ensino fundamental nas provas de habilidades metafonológicas e de leitura- PROHMELE. Revista da Sociedade Brasileira de Fonoaudiologia. [online]. 2009, vol.14, n.1, p. 56-68.

ESTILL, Clélia Argolo.Políticas Públicas da Dislexia. Associação Nacional de Dislexia (AND). Rio de Janeiro, outubro de 2016. Disponível em: <http://www. andislexia.org.br/docs/artigo-AND-8.pdf> Acesso em: 19 de jun. 2019.

FLICK, Uwe. Introdução à pesquisa qualitativa. Tradução de Joice Elias Costa. $3^{a}$ Ed. Porto Alegre: Artmed, 2009.

FREITAS, Gislene; REIS, Marlene Barbosa de Freitas. O uso do smartphone pela 
Geração Y: um olhar sobre os alunos do $5^{\circ}$ ano do Ensino Fundamental. Revista Tecnologias na Educação - Ano 10 - Número/Vol.25, Julho 2018.

GOOGLE PLAY. Silabando. 2017. Disponível em: <https://play.google.com/ store $/$ apps /details?id=com.appsbergman.silabando\&hl=pt_BR $>$ Acesso em: 01 de set. de 2018.

GROSSI, Márcia Gorett Ribeiro.; FERNANDES, Letícia Carvalho Belchior Emerick. Educação e tecnologia: o telefone celular como recurso de aprendizagem. Revista EccoS, São Paulo, n. 35, p. 47-65. set./dez. 2014. Disponível em <http:// www.redalyc.org/pdf/715/71535318003.pdf.> Acesso em: 16 set. 2018.

INSTITUTO ABCD. O que é dislexia? Disponível em: < https://www. institutoabcd.org.br/o-que-e-dislexia/> . Acesso em: 01 de out. de 2018.

JORNAL EDIÇÃO DO BRASIL. Versão digital. Dislexia atinge até $17 \%$ da população mundial. Belo Horizonte: Destaques Educação e Cultura, 05 de mai. de 2017.

LÉVY, Pierre. Cibercultura. São Paul:. Ed. 34, 1999.

MAIA, Heber (Org.). Necessidades Educacionais Especiais. Rio de Janeiro: Wak Editora, 2016.

MAINARDES, Jefferson. Reflexões sobre o objeto de estudo da política educacional. Laplage em Revista (Sorocaba), vol.4, n.1, jan. - abr. 2018 p.186 201 Disponível em: <http://www.laplageemrevista.ufscar.br/index.php/lpg/ article/view/399/649> Acesso em: 19 de jun. 2019.

MORÁN, José. Mudando a educação com metodologias ativas. In: Convergências Midiáticas, Educação e Cidadania: aproximações jovens. Coleção Mídias Contemporâneas. 2015. Disponível em: < http://www2.eca.usp.br/moran/wpcontent/uploads/2013/12/mudando_moran.pdf>. Acesso em: 03 maio 2018.

MOURA, Adelina Maria Carreiro. Apropriação do Telemóvel como Ferramenta de Mediação em Mobile Learning: Estudos de Caso em Contexto Educativo. 2010. 630 p. Tese (Doutorado em Ciências de Educação) - Universidade do Minho. Braga, Portugal, 2010. 
NAVAS, Ana Luiza. et al. Guia de boas práticas: do diagnóstico à intervenção de pessoas com transtornos específicos de aprendizagem. São Paulo: Instituto ABCD, 2017.

NADER, Alexandre Antonio Gili. O estado nas políticas educacionais e culturais em direitos humanos: o papel a ser desempenhado pela escola (pública). In: SILVEIRA, Rosa Maria Godoy. et al.Educação em Direitos Humanos: Fundamentos Teórico Metodológicos. PB-João Pessoa: UFPB, 2007.

PRENSKY, Marc. Aprendizagem baseada em jogos digitais. São Paulo: SENAC, 2012.

REIS, Marlene Barbosa de Freitas. Educação inclusiva: limites e perspectivas. Goiânia: Deescubra, 2006.

Política Pública, Diversidade e Formação Docente: uma interface possível. 2013. 279f. Tese (Doutorado em Ciências, Políticas Públicas, Estratégias e Desenvolvimento) - Universidade Federal do Rio de Janeiro-RJ, 2013.

SANCHEZ, Leila Franco. Dislexia: o que pensam os professores? Curitiba: UFPR, 2014. Disponível em: <https://acervodigital.ufpr.br/bitstream/ handle/1884/47203/R\%20-\%20E\%20-\%20LEILA \%20FRANCO \%20 SANCHEZ.pdf?sequence=1\&isAllowed $=\mathrm{y}>$ Acesso em: 01 set. de 2018.

SANTOS, Jucelio Soares dos.; COSTA, Rodrigo Alves. Análise de aplicações educacionais utilizadas na alfabetização de crianças com dislexia. CONEDU: Editora Realize, 2014. Disponível em: $<$ http://www.editorarealize.com.br/ revistas/conedu/trabalhos/Modalidade_1datahora_10_08_2014_00_12_00_ idinscrito_32449_c5c5bc4d9ebb2bf2b6acb39fb50b7fd1.pdf> Acesso em: 01 set. de 2018.

UNESCO.Diretrizes depolíticasdaUNESCOparaaaprendizagemmóvel.2014.45p. Disponível em: <http://unesdoc.unesco.org/images/0022/002277/227770por. pdf> Acesso em: 03 maio de 2016.

Coordenadoria Nacional para a Integração da Pessoa Portadora de Deficiência (CORDE). Declaração de Salamanca de princípios, política e prática para as necessidades educativas especiais. Brasília: CORDE, 1994. 
.Declaração mundial sobre educação para todos. Plano de ação para satisfazer as necessidades básicas de aprendizagem. Tailândia, 1990.

CARLA SALOMÉ MARGARIDA DE SOUZA é Pedagoga. Mestranda do Programa de Pós-Graduação Interdisciplinar em Educação, Linguagem e Tecnologias (PPG-IELT) da Universidade Estadual de Goiás/Câmpus Anápolis. Especialista em Docência Universitária; em Educação para a Diversidade e Cidadania; em Libras e Neuropsicopedagogia. Docente titular da UEG/Câmpus Inhumas e da Secretaria de Educação do Estado de Goiás. E-mail: c.salome@hotmail.com ORCID: http://orcid.org/0000-0002-3063-6785

MARLENE BARBOSA DE FREITAS REIS é Pós-Doutora em Gestão da Informação e Conhecimento pela Universidade do Porto, Portugal. Doutorado em Políticas Públicas, Estratégias e Desenvolvimento pela UFRJ. Pedagoga. Atualmente é professora titular da Universidade Estadual de Goiás (UEG). Docente permanente do Programa de Pós-Graduação Interdisciplinar em Educação, Linguagem e Tecnologias (PPG-IEL/UEG/Anápolis) e no curso de Pedagogia da UEG/Campus Inhumas. E-mail: marlenebfreis@hotmail.com ORCID: http://orcid.org/0000-0002-2213-7281

GISLENE DE FREITAS é Pedagoga. Mestranda do Programa de PósGraduação Interdisciplinar em Educação, Linguagem e Tecnologias (PPGIELT) da Universidade Estadual de Goiás/Câmpus Anápolis. Especialista em Aprendizagem e Diferenças. Professora da Secretaria de Educação do Estado de Goiás. E-mail: gislenefreitaso@hotmail.com

ORCID: http://orcid.org/0000-0002-8973-0557

LILIAN CRISTINA DOS SANTOS é Psicóloga. Mestranda do Programa de PósGraduação Interdisciplinar em Educação, Linguagem e Tecnologias (PPGIELT) da Universidade Estadual de Goiás/Câmpus Anápolis. Especialista em Gestão em saúde. Professora/tutora vinculada ao Centro de Ensino e Aprendizagem em Rede (CEAR), da Universidade Estadual de Goiás (UEG). E-mail: lilianpsi2012@gmail.com

ORCID: http://orcid.org/0000-0002-7226-0210 